Revista aSEPHallus de Orientação Lacaniana

Núcleo Sephora de Pesquisa sobre o Moderno e o Contemporâneo

ISSN 1809 - $709 \mathrm{X}$

\title{
A clínica do sujeito numa civilização plural: desafios à transmissão da psicanálise e ao saber-fazer do analista
}

Tania Coelho dos Santos

Orcid: https://orcid.org/0000-0002-5360-7864

Pós-doutorado no Departamento de Psicanálise de Paris VIII (Paris, França)

Professor Associado, nível IV no Programa de Pós-graduação em Teoria Psicanalítica /

UFRJ (Rio de Janeiro, Brasil)

Pesquisadora do CNPQ nível $1 \mathrm{C}$

Presidente do Instituto Sephora de Ensino e Pesquisa de Orientação Lacaniana /

ISEPOL (Rio de Janeiro, Brasil)

Psicanalista Membro da École de La Cause Freudienne (Brasil)

Membro da Escola Brasileira de Psicanálise e da Associação Mundial de Psicanálise (Paris, França) Membro da Associação Universitária de Pesquisa em Psicopatologia Fundamental (Rio de Janeiro, Brasil)

E-mail: taniacs@openlink.com.br

Uma questão que é cada vez mais urgente em nosso campo é a de aprofundar a teoria psicanalítica e aperfeiçoar nossas intervenções terapêuticas no campo da distinção entre as psicoses extraordinárias, as psicoses ordinárias e o, assim chamado, espectro autista. Se as neuroses de transferência e as psicoses extraordinárias despontaram com grande exuberância na civilização do século XIX, em nossos dias estamos as voltas com quadros clínicos mais difusos, de difícil classificação, nos quais os sinais discretos da psicose ou os indícios de autismo nos exigem ferramentas diagnósticas mais afiadas.

Michel Grollier em seu artigo sobre "As especificidades lacanianas na oposição psicose/autismo", destaca a abordagem da clínica das crianças autistas em torno de uma relação singular à voz do Outro, o lugar de origem dos significantes, que geralmente é encarnado pela mãe e por alguns parceiros da criança. Ele nos recorda que a questão, como dizia Lacan, é a de ver de onde eles ouviram aquilo que eles produzem para nós. Isto tem a ver com a clínica de Kanner, que ensinou a situar de onde vêm os enunciados surpreendentes dos autistas. Partindo deste ponto de vista, o autor nos apresenta as especificidades lacanianas da oposição psicose/autismo com base nos trabalhos de diversos psicanalistas que se destacam na área.

Rafael Campos Dored e Rosane Zétola Lustoza, por sua vez, trazem "Uma reflexão sobre a transferência dos psicóticos na teoria freudiana". O artigo trata de uma questão delicada. Por que Freud entendia que a transferência de pacientes psicóticos é inadequada para a clínica analítica? Os autores destacam uma importante descoberta. O mecanismo de defesa empregado pelo psicótico diante de uma frustração consiste em rechaçar uma representação da consciência e retornar a libido dessa representação de volta ao próprio ego, em pontos de fixação autoeróticos 
ou narcísicos. Na falta do mecanismo do recalque, o rechaço da representação produz um depósito de libido no Eu. A libido disponível para ser direcionada para o mundo externo se torna escassa, diminuindo a capacidade transferencial com o analista. Na esquizofrenia, a transferência é insuficiente; na paranoia, é de manejo impossível. Logo, Freud não recomenda a psicanálise para tratar psicóticos. Ela se encerra precocemente ou não apresenta ganhos terapêuticos. Os autores destacam que o mais importante é que Freud deixou um grande alicerce teórico sobre as psicoses e delegou à posterioridade a responsabilidade de elaborar uma forma de tratamento. É nesta via que os autores prosseguem com muito rigor.

E como abordar a diferença entre neurose e psicose na civilização plural sem retornar ao tema da diferença sexual? Aline Brentini Junqueira e Renata Wirthmann Gonçalves Ferreira em seu artigo intitulado "O deslumbramento que representa dois paradigmas distintos do impossível: um estudo da desigualdade entre os sexos", também trazem elementos importantes para entender melhor as relações entre experiências subjetivas de devastação e um gozo mais além do sexual. No rastro das consequências psíquicas da diferença anatômica entre os sexos, as autoras destacam a presença de traços delas na obra $O$ des/umbramento, de Marguerite Duras. Ressaltam a diferença entre o deslumbramento amoroso dentro da lógica fálica e a devastação desestruturante mais além da lógica fálica. Em particular, no que diz respeito aos dois personagens principais, Hold, do lado do masculino, e Lol, do feminino. Propõem que gozo fálico é aquilo que Hold tem a dizer sobre Lol e seu impulso constante por "dizê-la", causando o que se denomina como deslumbramento, o qual constitui o sintoma masculino. Para não ter de lidar com sua própria falta, o homem se ocupa da falta na mulher, de lhe oferecer semblantes. Fica deslumbrado por essa falta fálica e causa deslumbramento à mulher com os semblantes que oferece. A parceria sintomática entre um homem e uma mulher por meio do efeito de deslumbramento próprio à lógica fálica, concede ao portador do falo a responsabilidade de oferecer semblantes, ditos e discursos à sua parceira faltosa na partilha sexual. Entretanto, o fracasso do deslumbramento leva à devastação, uma experiência inquietante que evidencia os danos da permanência da mulher em uma posição de objeto sustentada por tais semblantes e ditos.

Também Márcia Infante Vieira aborda as consequências psíquicas da diferença sexual em seu artigo intitulado "Transmissão em psicanálise", motivada pelos radicalismos discursivos que se manifestam de modo cada vez mais extremado numa sociedade que se pretende pós-moderna e plural. Pretende responder à questão sobre o caráter conservador ou revolucionário da psicanálise no que se refere à diferença sexual. Este tema frequenta a mídia atualmente. Ressaltando que nos círculos feministas radicais Freud é considerado misógino, a autora propõe um recuo histórico na teoria freudiana enfocando os efeitos psíquicos da distinção anatômica entre os sexos. 0 eixo orientador desse trabalho é a hipótese de que é impossível levar essa questão adiante sem articular a prática da psicanálise com a sua transmissão. A leitura deste trabalho permite perceber 
que a psicanálise é a sua clínica e não um discurso filosófico. Por essa razão, o diálogo com os movimentos sociais é tão difícil. Somente a wirklichkeit, a realidade efetiva do que se manifesta como sintoma, lapso e ato falho pode nos convencer da dimensão inconsciente da subjetividade humana.

A experiência da adolescência na civilização plural tem muito a ensinar sobre os impasses subjetivos e as soluções possíveis. Não são apenas os discursos radicais que levam à segregação e a impasses subjetivos cada vez mais acentuados. Também as nomeações que segregam podem ter esse efeito quando o sujeito que é considerado problema não é chamado a tomar a palavra e falar sobre si. Ana Lydia Bezerra Santiago, Cristiane de Freitas Cunha Grillo e Izabela de Freitas Cunha Lins Albuquerque abordam os adolescentes, as escolas e os impasses através de um recorte da clínica no "Janela da Escuta". Mais uma vez, o discurso analítico demonstra ser capaz de produzir respostas ao mal-estar muito diferentes das que outros discursos oferecem. A análise dos impasses gerados pelas demandas de encaminhamento dos adolescentes da escola para a saúde, o papel do atendimento a essas demandas e a postura dos adolescentes diante da experiência foi efetuado através da análise de dois casos. Constatou-se a necessidade e a importância de se ofertar a esses adolescentes uma "Janela da Escuta" de suas verdadeiras demandas, onde, por meio do convite à fala, puderam se assumir como protagonistas de suas questões e se reposicionar frente à situação em que se encontravam, tornando possível o aparecimento de sua singularidade.

Bruna Simões de Albuquerque, Lisley Braun e Ana Lydia Santiago prosseguem nesta mesma via de pesquisa/intervenção, no artigo intitulado: "Uma Conversação com os melhores alunos: do sintoma como modo de funcionamento ao mais além da segregação". Apresentam a experiência realizada com alunos da rede pública por meio da metodologia da Conversação de Orientação Psicanalítica. Encontraram-se com os "melhores" alunos de uma escola e com os ruídos em torno dessa nomeação. Por meio desse resto, desse ruído que retorna, atrapalhando o processo de aprendizagem e de convivência, verificamos os efeitos de segregação que mantinham os alunos em uma guerra interna. Uma leitura do sintoma como modo de funcionamento na escola permitiu recolher os efeitos plurais de segregação. O objetivo é escutar o sintoma para então operar a partir dele. Pois estes sintomas podem dar ensejo a destinos mortíferos. É preciso ultrapassar a sensação de impotência generalizada diante do que não funciona.

Muito a propósito, o tema das relações entre o exercício da soberania e a subjetivação da lei na civilização onde as referências são pluralizadas, arrefecem seu poder coercitivo. Bernardo Micherif Carneiro e Ana Lydia Bezerra Santiago, no artigo intitulado "Mais uma vez, o soberano!: leitura psicanalítica da teoria do estado de exceção", abordam a dimensão da soberania e seus efeitos sobre a subjetivação da pulsão e do inconsciente. Giorgio Agamben identifica uma recusa do campo do Direito em reconhecer uma esfera da ação humana que é em si mesma extrajurídica. Para ultrapassar essa barreira, ele eleva uma frase de Schmitt à dignidade de um matema: 
"Soberano é quem decide sobre o estado de exceção". Matema que articula três elementos indissociáveis: soberania, decisão e estado de exceção. A montagem de sua teoria sobre o estado de exceção se estrutura na articulação entre três elementos fundamentais, os quais definirão o percurso da discussão: primeiro, ele indaga a interseção entre o político e o jurídico; em seguida, questiona a interseção entre o direito e o vivente; e, finalmente, examina a inclusão da vida na política, o que o permite refletir sobre o que significa agir politicamente. Os autores nomeiam política, direito e vida como os três elos que se enodam a partir do pathos da soberania na civilização moderna. E se perguntam: como ajustar essa amarração borromeana à subjetividade de nossa época? Ao que nós acrescentaríamos, seria ainda borromeana essa amarração subjetiva nos dias de hoje? Não seria melhor falar em predominância de amarrações não borromeanas? Não estamos no tempo das suplências à função do Nome-do-Pai?

Para concluir, voltamos ao ponto de partida. O problema do diagnóstico, da diferença entre neurose, psicose e autismo na clínica psicanalítica nos dias de hoje muitas vezes se apresenta de forma urgente. Os casos clínicos se tornaram menos classificáveis. As amarrações menos borromeanas $\mathrm{O}$ psicanalista precisa afiar suas ferramentas, voltamos a dizer, quando não há muito tempo para decidir como intervir. Manuella Itapary Ribeiro Moreira e Tania Coelho dos Santos, no artigo intitulado: "Psicanálise aplicada à instituição: a prática clínica no hospital geral", recordam que essa prática ensina sobre a particularidade do caso, o diagnóstico e o tratamento da urgência subjetiva de um sujeito ou de seus familiares diante de uma doença grave. No ambiente hospitalar são desencadeadas angústias mais ou menos agudas como resposta subjetiva, neurótica ou psicótica, ao encontro com o desamparo e a fragilidade do corpo. Saber distingui-las é essencial. É isso que nos ensina essa prática todos os dias.

A resenha acerca do artigo de Freud intitulado "Dostoeivski e o Parricídio", de Nathalia Christina Martins vem fechar com chave de ouro esse número da nossa revista. Nunca é tarde demais para recordar que a essência de nossa prática é a dimensão do real, esse pathos pulsional que habita o mais íntimo de cada um. Se o sonho é a estrada real para o inconsciente, são os impasses trágicos que traçam o caminho mais rápido para o encontro do real.

Agradeço em nome do corpo editorial de aSEPHallus a contribuição de todos os autores para a excelente qualidade deste número de nossa revista. 
Citação/Citation: Coelho dos Santos, T. (mai. 2019 a out. 2019). A clínica do sujeito numa civilização plural: desafios à transmissão da psicanálise e ao saber-fazer do analista. Revista aSEPHallus de Orientação Lacaniana, 14(28), 1-5. Disponível em www.isepol.com/asephallus. Doi: 10.17852/1809709x.2019v14n28p01-05

Editor do artigo: Tania Coelho dos Santos.

Recebido/Received: 02/08/2019 / 08/02/2019.

Aceito/Accepted: 04/10/2019 / 10/04/2019.

Copyright: ( 2019 Associação Núcleo Sephora de Pesquisa sobre o moderno e o contemporâneo. Este é um artigo de livre acesso, que permite uso irrestrito, distribuição e reprodução em qualquer meio, desde que $o$ autor e a fonte sejam citados/This is an open-access article, which permites unrestricted use, distribution, and reproduction in any medium, provided the author and source are credited. 